\title{
A patient previously treated with ALK inhibitors for central nervous system lesions from ALK rearranged lung cancer: a case report
}

This article was published in the following Dove Press journal:

OncoTargets and Therapy

12 October 2016

Number of times this article has been viewed

\author{
Jumpei Kashima' \\ Yusuke Okuma ${ }^{1,2}$ \\ Tsunekazu Hishima ${ }^{3}$ \\ 'Department of Thoracic Oncology \\ and Respiratory Medicine, Tokyo \\ Metropolitan Cancer and Infectious \\ diseases Center Komagome Hospital; \\ ${ }^{2}$ Division of Oncology, Research \\ Center for Medical Sciences, The \\ Jikei University School of Medicine; \\ ${ }^{3}$ Department of Pathology, Tokyo \\ Metropolitan Cancer and Infectious \\ diseases Center Komagome Hospital, \\ Tokyo, Japan
}

Background: Patients with anaplastic lymphoma kinase (ALK)-rearranged non-small-cell lung cancer (NSCLC) are now preferentially treated with tyrosine kinase inhibitors (TKIs). However, patients treated with ALK inhibitors end up with acquired resistance.

Case presentation: We present a patient with recurrent ALK-rearranged NSCLC that developed multiple brain metastases and meningitis carcinomatosa after sequential treatment with several lines of cytotoxic chemotherapy, crizotinib, and alectinib. After the patient underwent retreatment with crizotinib as salvage therapy because of poor performance status, the intracranial metastatic foci and meningeal thickening were shrank within 1 week.

Conclusion: Our experience with this case suggests that alectinib may restore sensitivity to crizotinib or amplified pathway such as MET which bestowed alectinib resistance was inhibited with crizotinib.

Keywords: alectinib, anaplastic lymphoma kinase rearrangement, crizotinib

\section{Background}

Over the past decade, molecular-targeted treatment using tyrosine kinase inhibitors (TKIs) has greatly improved the prognoses of patients with non-small-cell lung cancer (NSCLC) harboring certain genetic mutations or rearrangement. Crizotinib (PF-02341066) is one of the TKIs that inhibits anaplastic lymphoma kinase (ALK), MET, and ROS $1 ; 1$ it has been approved by the US Food and Drug Administration for the treatment of ALK-positive NSCLC. A Phase I trial has demonstrated the promising efficacy of crizotinib: it has achieved progression-free survival times of $>10$ months in advanced ALK-positive non-squamous NSCLC patients. ${ }^{2}$ However, crizotinib is considered to have poor activity against metastases in the central nervous system (CNS). Among the patients enrolled in the PROFILE 1001 and 1005 studies in whom the disease progression occurred, the most common site of single-organ progression was the brain. ${ }^{3}$ Case reports have also shown a low level of cerebrospinal fluid (CSF) concentrations of crizotinib $(0.06 \%-0.26 \%$ of serum levels $) .4$. ${ }^{4,5}$ wo mechanisms have been suggested to explain the progression of tumors treated with crizotinib; these are an acquired secondary mutation in the ALK gene that is known to confer resistance to crizotinib, and activation of alternative tumor-growth pathways such as those involving epidermal growth factor (EGFR) and KIT. ${ }^{6,7}$ Alectinib (CH5424802) has highly selective inhibitory activity against ALK; a previous study has reported its effectiveness in patients pretreated with other ALK inhibitors, especially in those with brain metastases. ${ }^{8}$ However, an in vitro study has shown that alectinib also induced other 
cell-proliferation pathways; in addition, no consensus has been reached regarding the recommended treatment regimen when TKIs fail to control diseases, and treatment strategies including alectinib against crizotinib-resistant NSCLC has been proposed. ${ }^{9}$ Among patients harboring EGFR-mutated advanced NSCLC, rechallenge treatment with EGFR-TKI has been demonstrated to be active. ${ }^{10}$ However, there are limited published data regarding ALK-rearranged NSCLC because it is a relatively rare histological subtype.

Herein, we present a patient with multiple brain metastases and meningitis carcinomatosa who was heavily treated with cytotoxic chemotherapy and previously treated with crizotinib and alectinib in an end-of-life setting, and had a radiologically demonstrated response to rechallenge with crizotinib.

\section{Case presentation}

A 48-year-old East-Asian man, who was previously a light smoker, underwent resection of a recurrent adenocarcinoma at pT1N0M0 stage IA in his right lower lobe of the lung. The patient was diagnosed as having recurrence in the right supraclavicular and axillar lymph nodes, and right thoracic wall. Although no EGFR mutations were observed, the echinoderm microtubule-associated protein-like (EML) 4-ALK fusion gene was detected in 2009 at the Tokyo Metropolitan Cancer and Infectious diseases Center Komagome Hospital (Figure 1). The patient was treated with chemotherapy consisting of cisplatin $\left(75 \mathrm{mg} / \mathrm{m}^{2}\right.$, day 1 , every 3 weeks $)$ and pemetrexed ( $500 \mathrm{mg} / \mathrm{m}^{2}$, day 1 , every 3 weeks) from June 2009 for four cycles and subsequent pemetrexed maintenance therapy (500 mg/m², day 1 , every 3 weeks) for six cycles, resulting in a partial response. Thereafter, he received palliative

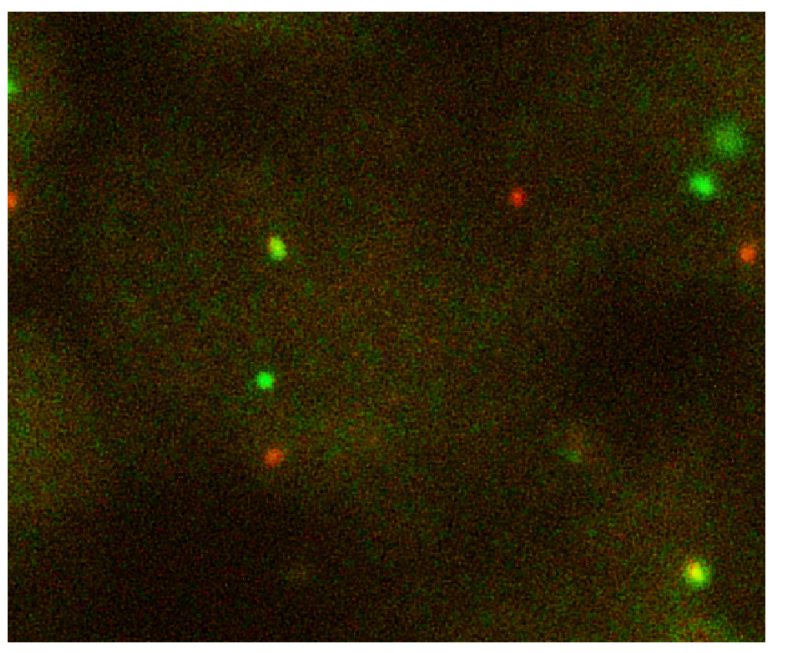

Figure I Fluorescence in situ immuno-hybridization signals of ALK. Note: Split red and green signals indicate broken-apart ALK gene. radiotherapy and participated in a clinical trial and during which he was treated with erlotinib (150 mg/day) \pm tivantinib (ARQ197, 720 mg/day) from August 2012 until March 2013. Then, we started to treat the patient with crizotinib at a dose of $250 \mathrm{mg}$ twice daily. Grade 3 QTc prolongation was observed; consequently, we reduced the dose to $200 \mathrm{mg} /$ day. Consistent anorexia with vomiting was seen during treatment for 9 months until progression. The patient was treated with three cycles of docetaxel ( $60 \mathrm{mg} / \mathrm{m}^{2}$, day 1 , every 3 weeks), which ended in multiple brain metastases accompanied by Cushing syndrome; he was subsequently treated with whole brain irradiation. Nine cycles of nanoparticle-albumin bound paclitaxel (100 mg/m², weekly) were administered, followed by alectinib (600 mg/day) from December 2014 for 6 months, resulting in a partial response.

During the third cycle of gemcitabine $\left(1,000 \mathrm{mg} / \mathrm{m}^{2}\right.$, days $1,8,15$, every 4 weeks) as the sixth line of chemotherapy, the patient had gradually presented with weakness and appetite loss accompanied by neck stiffness; therefore, we suspected meningitis carcinomatosa. Laboratory data demonstrated no significant abnormality, while the multiple enhanced lesions appeared with meningeal thickening (Figure 2A and B). As salvage therapy, considering the patient's poor performance status, we administered $250 \mathrm{mg}$ of crizotinib twice daily from August 2015. One week after the commencement of crizotinib treatment, magnetic resonance imaging revealed shrinkage of metastatic foci and peritumoral edema in the brain (Figure 2D) and meningeal thickening (Figure 2E). However, hepatic metastasis had progressed (Figure 2C and F) and the patients' nausea and poor performance status were not greatly improved. Crizotinib treatment had to be discontinued and the patient was transferred to the palliative care unit. The nausea was slightly improved; however, he died 1 week later because of respiratory failure stemming from aspiration.

\section{Discussion}

We reported the CNS response of a patient after rechallenge crizotinib treatment, who had been previously heavily treated with crizotinib, alectinib, and cytotoxic chemotherapy. Approximately $5 \%$ of NSCLC is ALK positive, and treatment involving TKIs with ALK inhibitory activity has drastically improved the prognosis and progression-free survival of patients. ${ }^{11}$ Treatment involving crizotinib has been widespread for patients with ALK-rearranged NSCLC; however, disease progression inevitably occurs during treatment even if an initial response was achieved. Several mechanisms that confer resistance against crizotinib have been reported, 

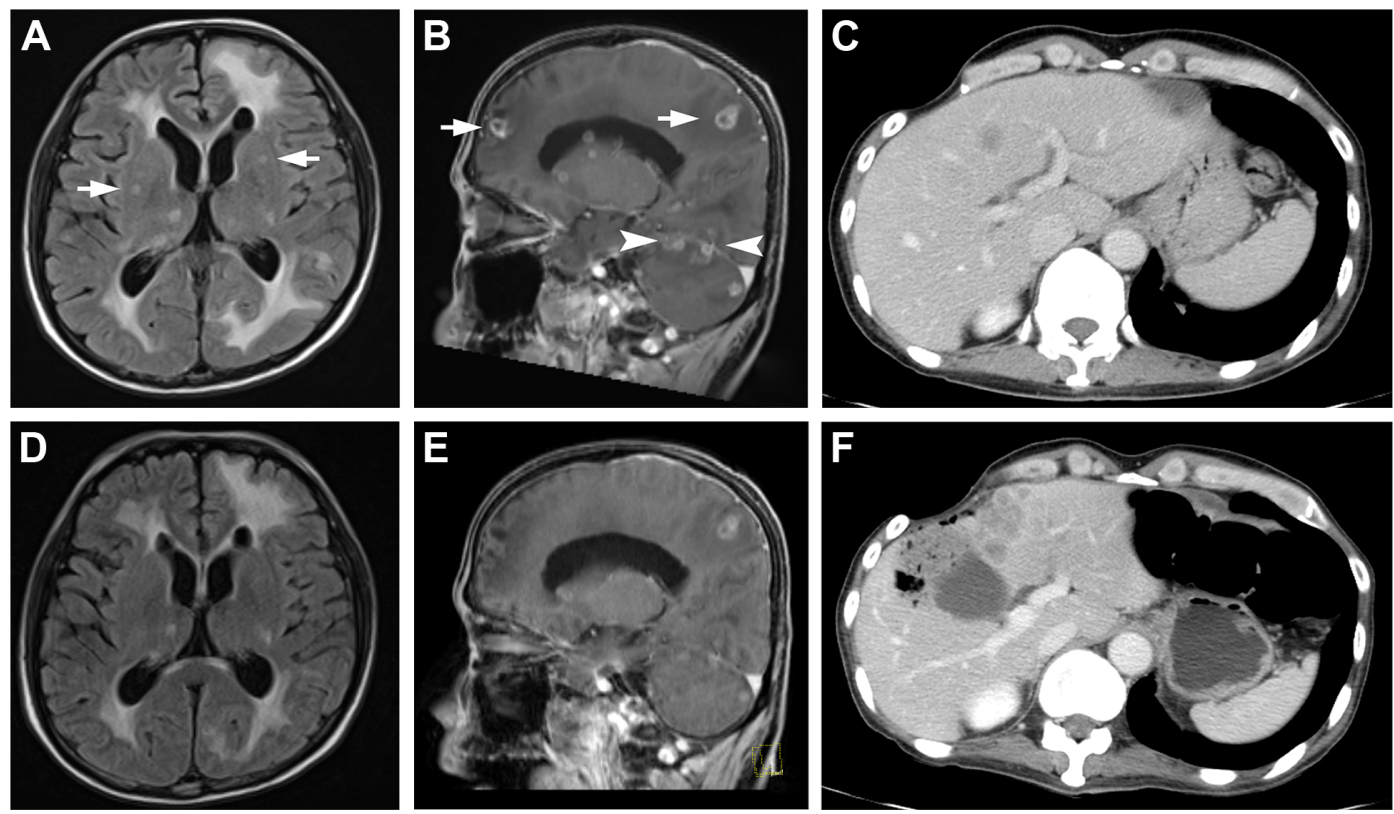

Figure 2 Magnetic resonance imaging scans depicting the response of intracranial metastases and change in meningeal thickness after crizotinib rechallenge treatment. Notes: (A, B) Cerebral metastatic foci and meningeal thickness, and (D, E) positive response to the second administration of crizotinib after I week. (C, F) Progression of hepatic metastasis. Arrow indicates brain metastasis, and the arrowhead indicates leptomeningeal metastasis.

including secondary mutation of $\mathrm{ALK}^{12}$ and activation of other cell-proliferation pathways. ${ }^{13,14}$ Although there have been two reported cases involving successful tumor control after second challenge with crizotinib involving pretreatment with pemetrexed, ${ }^{15,16}$ there has been no study that has reported that crizotinib had a tumor regression effect after the administration of both crizotinib and alectinib.

Although CNS metastases in advanced NSCLC frequently occur in patients receiving crizotinib treatment, systemic disease is well controlled. In our case, the first administration of crizotinib treatment failed because of hepatic metastases; alectinib was administered for progression of hepatic lesions, and crizotinib rechallenge seemed effective against CNS metastases, whereas the hepatic disease did not respond. This clinical course appeared to be contrary to most of the previously reported cases with ALK-positive NSCLC. We believe that there were three reasons for this, as follows: 1) alectinib (or other cytotoxic drugs) restored tumor sensitivity to crizotinib; 2) the genetic profile of metastatic tumors varied in different organs; and 3) several lines of chemotherapy and whole brain radiotherapy disrupted the permeability of the blood-brain barrier. In contrast to crizotinib, alectinib is a selective ALK inhibitor; an in vitro study has shown that alectinib activates alternative pathways such as those involving MET and EGFR. If these phenomena also occurred in this presented case, cell proliferation pathways activated by alectinib administration were inhibited by the multiple kinase inhibitor, crizotinib, resulting in a good response regarding the CNS metastases. A recent report showed that a certain resistance mutation in the ALK gene acquired during treatment with alectinib was sensitive to ceritinib, another second-generation ALK-TKI. ${ }^{17}$ So, such mutation might also have occurred in this case, which provided sensitivity to crizotinib, after alectinib administration. Unfortunately, we could not investigate certain genetic expressions or acquired gene mutations because of the lack of tissue samples from the brain.

Genetic variation in metastatic breast and colon cancers has previously been studied from organ to organ. Hepatic metastases in our case were detected during the first crizotinib treatment; they grew despite the administration of alectinib, and did not respond to crizotinib rechallenge, even though it was effective for the treatment of disease in the brain. This finding may imply that a difference between hepatic and intracranial metastases exists regarding genetic mutation or protein expression, which endows tumor resistance to TKIs.

Crizotinib has been suggested to have poor penetration characteristics regarding the CNS; brain metastases experienced as the first site of metastasis during treatment are common in $\leq 46 \%$ of patients. ${ }^{3}$ The National Comprehensive Cancer Network guidelines suggest that stereotactic radiotherapy should be simultaneously administered in isolated CNS disease cases where disease progression is observed with crizotinib continuation. ${ }^{18}$ Several courses of chemotherapy and whole brain irradiation were tried before 
crizotinib rechallenge; thus, one or more elements of the previous treatments might have improved the permeability of the blood-brain barrier to crizotinib. Therapies such as intrathecal trastuzumab are now being evaluated in clinical trials; an alternative mode of administration that improves the transitional activity of the existing crizotinib therapy may provide more favorable results for brain metastases.

\section{Conclusion}

We reported a patient with ALK-positive NSCLC who was previously treated with crizotinib, alectinib, and cytotoxic drugs, and demonstrated a good response regarding brain metastasis and carcinomatosa meningitis after crizotinib rechallenge. This case may suggest that alectinib restored tumor susceptibility to crizotinib, especially with regard to CNS metastases, by activating alternative cell-proliferation pathways.

\section{Consent to publish}

Written informed consent was obtained from the patient for publication of this case report and the accompanying images. This report was approved by the Ethics Committee of Tokyo Metropolitan Cancer and Infectious diseases Center Komagome Hospital.

\section{Acknowledgment}

The authors would like to thank Edanz (http://www. edanzediting.co.jp) for English language editing.

\section{Authors' contributions}

JK acquired the clinical data and drafted the manuscript. YO was responsible for the clinical management of the patient. $\mathrm{TH}$ was responsible for pathological diagnosis. JK, YO, and $\mathrm{TH}$ were responsible for interpretation of the data and critical revision of the manuscript. All authors have read and approved the final manuscript.

\section{Disclosure}

The authors report no conflicts of interest in this work.

\section{References}

1. Cui JJ, Tran-Dubé M, Shen H, et al. Structure based drug design of crizotinib (PF-02341066), a potent and selective dual inhibitor of mesenchymal-epithelial transition factor (c-MET) kinase and anaplastic lymphoma kinase (ALK). J Med Chem. 2011;54(18):6342-6363.
2. Camidge DR, Bang YJ, Kwak EL, et al. Activity and safety of crizotinib in patients with ALK-positive non-small-cell lung cancer: updated results from a phase 1 study. Lancet Oncol. 2012;13(10):1011-1019.

3. Otterson GA, Riely GJ, Tsang Shaw A, et al. Clinical characteristics of ALK+ NSCLC patients (pts) treated with crizotinib beyond disease progression (PD): Potential implications for management. J Clin Oncol. 2012;30(suppl; abstr 7600).

4. Costa DB, Kobayashi S, Pandya SS, et al. CSF concentration of the anaplastic lymphoma kinase inhibitor crizotinib. J Clin Oncol. 2011; 29(15):e443-e445.

5. Metro G, Lunardi G, Floridi P, et al. CSF concentration of crizotinib in two ALK-positive non-small-cell lung cancer patients with CNS metastases deriving clinical benefit from treatment. J Thorac Oncol. 2015; 10(5):e26-e27.

6. Katayama R, Shaw AT, Khan TM, et al. Mechanisms of acquired crizotinib resistance in ALK-rearranged lung cancers. Sci Transl Med. 2012;4(120):120ra17-ra17.

7. Doebele RC, Pilling AB, Aisner DL, et al. Mechanisms of resistance to crizotinib in patients with ALK gene rearranged non-small cell lung cancer. Clin Cancer Res. 2012;18(5):1472-1482.

8. Gadgeel SM, Gandhi L, Riely GJ, et al. Safety and activity of alectinib against systemic disease and brain metastases in patients with crizotinibresistant ALK-rearranged non-small-cell lung cancer (AF-002JG): results from the dose-finding portion of a phase $1 / 2$ study. Lancet Oncol. 2014;15(10):1119-1128.

9. Toyokawa G, Seto T. ALK inhibitors: what is the best way to treat patients with ALK+ non-small-cell lung cancer? Clin Lung Cancer. 2014; 15(5):313-319.

10. Tomizawa Y, Fujita Y, Tamura A, et al. Effect of gefitinib re-challenge to initial gefitinib responder with non-small cell lung cancer followed by chemotherapy. Lung Cancer. 2010;68(2):269-272.

11. Shaw AT, Kim DW, Nakagawa K, et al. Crizotinib versus chemotherapy in advanced ALK-positive lung cancer. $N$ Engl J Med. 2013; 368(25):2385-2394.

12. Choi YL, Soda M, Yamashita Y, et al. EML4-ALK mutations in lung cancer that confer resistance to ALK inhibitors. $N$ Engl $J$ Med. 2010;363(18):1734-1739.

13. Lennerz JK, Kwak EL, Ackerman A, et al. MET amplification identifies a small and aggressive subgroup of esophagogastric adenocarcinoma with evidence of responsiveness to crizotinib. J Clin Oncol. 2011;29(36):4803-4810.

14. Yamada T, Takeuchi S, Nakade J, et al. Paracrine receptor activation by microenvironment triggers bypass survival signals and ALK inhibitor resistance in EML4-ALK lung cancer cells. Clin Cancer Res. 2012;18(13):3592-3602.

15. Browning ET, Weickhardt AJ, Camidge DR. Response to crizotinib rechallenge after initial progression and intervening chemotherapy in ALK lung cancer. J Thorac Oncol. 2013;8(3):e21.

16. Schrödl K, von Schilling C, Tufman A, Huber RM, Gamarra F. Response to chemotherapy, reexposure to crizotinib and treatment with a novel ALK inhibitor in a patient with acquired crizotinib resistance. Respiration. 2014;88(3):262-264.

17. Ou SH, Greenbowe J, Khan ZU, et al. I1171 missense mutation (particularly $\mathrm{I} 1171 \mathrm{~N}$ ) is a common resistance mutation in ALK-positive NSCLC patients who have progressive disease while on alectinib and is sensitive to ceritinib. Lung Cancer. 2015;88(2):231-234.

18. Ettinger DS, Akerley W, Borghaei $\mathrm{H}$, et al. Non-small cell lung cancer, version 2.2013. J Natl Compr Canc Netw. 2013;11(6):645-653. 
OncoTargets and Therapy

\section{Publish your work in this journal}

OncoTargets and Therapy is an international, peer-reviewed, open access journal focusing on the pathological basis of all cancers, potential targets for therapy and treatment protocols employed to improve the management of cancer patients. The journal also focuses on the impact of management programs and new therapeutic agents and protocols on The manuscript management system is completely online and includes a very quick and fair peer-review system, which is all easy to use. Visit http://www.dovepress.com/testimonials.php to read real quotes from published authors.

Submit your manuscript here: http://www.dovepress.com/oncotargets-and-therapy-journal 